\title{
REPRESENTAÇÕES E VIVÊNCIAS DA DOCÊNCIA EM PROFESSORES DO ENSINO SUPERIOR DE UMA FACULDADE PRIVADA DE CACOAL-RO
}

\author{
REPRESENTACIÓN Y VIVENCIAS DE LA ENSEÑANZA EN DOCENTES DE \\ EDUCACIÓN SUPERIOR DE UNA UNIVERSIDAD PRIVADA DE CACOAL-RO
}

\author{
REPRESENTATIONS AND LIVING AT TEACHERS ABOUT THE \\ TEACHING IN PRIVATE UNIVERSITY OF THE CACOAL-RO
}

\author{
Cleber Lizardo de ASSIS ${ }^{1}$ \\ Valdimari PACHECO ${ }^{2}$
}

RESUMO: O trabalho docente em nível superior tem passado por transformações sociais e políticas, tais como as novas exigências impostas pelas reformas educacionais e de mudanças sociais na representação e na forma de desvalorização deste profissional. Objetiva-se identificar as Representações do Ato Docente em Professores Universitários de uma Instituição Privada de Ensino Superior. Método: Pesquisa exploratória, com dados coletados junto a 04 (quatro) professores do ensino superior do município de Cacoal-RO, através de questionário semiestruturado, tratado por Análise de Conteúdo. Percebeu-se elementos caracterizadores do "mal-estar docente", se referindo a "acúmulo de tarefas", "cansaço", "falta de compromisso do aluno", "estresse" e outros relacionados a conflitos entre professores, alunos e instituição. Para enfrentar tais dificuldades, os docentes adotam posturas que variam entre a indiferença e a preocupação excessiva, com certo abalo "emocional" contrabalanceado com o "prazer" proporcionado por outros elementos da profissão. Conclui-se que, há significados e sentimentos frente ao ato docente, marcados por uma consciência da "carga" de responsabilidade diante do aluno, instituição e sociedade, idealismo profissional, com o reconhecimento/desconhecimento marcando o motivo ou desmotivo de trabalhar, certo conhecimento e vivência de "malestar" relacionados a elementos que afetam a saúde mental, mas quase sem nenhuma forma de lidar com a situação.

PALAVRAS-CHAVE: Trabalho. Docência no Ensino Superior. Saúde Mental. Psicologia.

RESUMEN: La enseñanza de trabajo en la educación superior ha experimentado cambios sociales y políticos, como los nuevos requisitos impuestos por las reformas educativas y de los cambios sociales en la representación y en la forma de devaluación de este profesional. El objetivo es identificar la Representación del acto de Enseñanza en Profesores Universitarios de una institución privada de educación superior. Método: La investigación exploratoria, con datos recogidos de los cuatro (04) de los profesores de educación superior en el municipio de Cacoal RO, través de cuestionario

${ }^{1}$ Doutor em Psicologia pelaUniversidad del Salvador-USAL. Docente de Psicologia da Faculdade de Ciências Biomédicas de Cacoal -FACIMED -RO. Email: kebelassis@yahoo.com.br

${ }^{2}$ UNESC-RO. Email: kebelassis@yahoo.com.br 
semiestructurado, tratados mediante Análisis de Contenido. Se percibió elementos característicos del "malestar docente", en referencia a la "acumulación de tareas", "fatiga", "falta de compromiso del estudiante", "estrés" y otros conflictos relacionados entre profesores, estudiantes y la institución. Para hacer frente a estas dificultades, los maestros adoptan actitudes que van desde la indiferencia y la preocupación por cierto choque "emocional", contrarrestado con "placer" proporcionada por otros elementos de la profesión. En conclusión, hay significados y sentimientos hacia el acto de enseñanza, marcadas por la conciencia de la "carga" de la responsabilidad en el estudiante, la institución y la sociedad, el idealismo profesional, el reconocimiento/desconocimiento que marca el motivo o desmotivo al trabajo, el conocimiento correcto y la experiencia de "malestar" en relación con los elementos que afectan a la salud mental, pero casi no hay manera de lidiar con la situación.

PALAVRAS CLAVE: Trabajo. La enseñanza en la Educación Superior. Salud mental. Psicología.

ABSTRACT: The teaching at the college level has undergone social and political changes, such as new requirements imposed by the educational reforms of social change in the representation and how undervalued this person. The objective is to identify the Teacher Act Representations in University Teachers of Private Institution of Higher Education. Method: exploratory, with data collected from four (04) of higher education teachers at Cacoal-RO, through semi-structured questionnaire, treated by Content Analysis. It was perceived characteristic elements of "teacher malaise", referring to "work accumulation", "tiredness", "lack of commitment of the student", "stress" and other related conflicts between teachers, students and the institution. To address these difficulties, teachers adopt attitudes ranging from indifference and preoccupation with certain shock "emotional" countered with "pleasure" provided by other elements of the profession. In conclusion, there are meanings and feelings towards the teaching act, marked by an awareness of the "burden" of responsibility to the student, institution and society, professional idealism, recognizing/ignorance marking the reason or desmotivo to work, right knowledge and experience of "discomfort" related to elements that affect mental health, but almost no way to deal with the situation.

KEYWORDS: Work. Teaching in High Education. Mental health. Psychology.

\section{Introdução}

Sabe-se que o trabalho do professor, de uma maneira geral, enfrenta dificuldades, sejam elas no reconhecimento financeiro, condições de trabalho e relações interpessoais com colegas, instituição ou corpo administrativo e professor-aluno. Relacionado a estes e outros fatores, a profissão docente que nas décadas passadas era vista como uma profissão sublime e da qual profissionais, pais, alunos e a própria sociedade admirava e reconhecia, foi perdendo seu status, chegando a uma situação lastimável de descrédito e perdendo o reconhecimento, tornando-se uma profissão preterida entre as crianças 
quando indagadas sobre o sonho de "ser quando crescer". Esses e outros fatores podem levar o profissional da docência a sentir-se cada dia mais desmotivado, desacreditado de sua função, acarretando a longo prazo o adoecer psíquico e físico.

De posse destes pressupostos, somados à falta de motivo, significação e o elevado número de doenças que tem assolado esses profissionais, e por acreditar que a psicologia pode auxiliar os profissionais da docência a reencontrar o sentido/significado da profissão, e considerando a relevância em tratar de uma temática atual como o sofrimento psíquico, o ato docente e os significados e representações da docência em professores universitários, interessa-nos identificar as representações sobre a docência, os elementos motivadores, os desmotivadores e a presença de possíveis elementos geradores de "malestar docente".

O trabalho, historicamente, é determinante para a construção do sujeito como ser social, é por meio desse que o sujeito projeta suas realizações, é fonte de renda de sobrevivência e deve estar atrelado a fonte de prazer, quando não se torna fonte de sofrimento (MARTINS e OLIVEIRA, 2006). No entanto, referindo-se ao trabalho docente, percebe-se ao longo dos anos, várias transformações que influenciam diretamente sobre o fazer profissional, gerando dúvidas entre o fazer ideal e o real do trabalho do professor, de modo que, na atualidade, a profissão docente passa por situações tensas em termos de uma busca de identidade (Paschoalino, 2007). Neste sentido, "Nossa categoria passa por uma desmoralização: somos incompetentes, somos descomprometidos, somos uma categoria muito heterogênea. A culpa está em todos, menos no poder que gera essa situação" (DOTTI, 1992 apud PASCHOALINO, 2007, p. 4-5). Assim, a profissão docente torna-se cada vez mais desmotivante, enquanto o professor que na Idade Média possuía valor sacerdotal (ou mesmo em décadas passadas), foi perdendo tal valor, chegando a ser uma profissão desprestigiada (SORATTO e OLIVIER-HECKLER, 2006, p. 97).

A correlação entre a Psicologia e o Trabalho ${ }^{3}$ vêm se articulado à importância do mesmo na constituição da identidade dos sujeitos, assim como o trabalho se torna responsável por um grande número dos casos de males da psiquê humana, posto que o trabalho é parte inerente do ser humano, faz parte da construção da subjetividade humana e também modo que "o sujeito tem acesso ao reconhecimento de si mesmo e,

${ }^{3}$ Uma importante referência para o grande tema do trabalho e a saúde mental do trabalhador encontra-se em: DEJOURS, Christophe. A loucura do trabalho: estudo de psicopatologia do trabalho. 5. ed. São Paulo: Cortez, 1992. 
simultaneamente, pela via da alteridade, ao inelutável reconhecimento do outro" (VIEIRA, BARROS e LIMA, 2007, p. 156). No entanto, além de elemento importante "na constituição do sujeito e na sua inserção social como estratégia de saúde e como associado ao adoecimento mental" (JACQUES, 2003, p. 99), seja associado aos grandes desafios ao psiquismo humano, por não ser capaz de corresponder às exigências lançadas a si, e o resultado é um sentimento de desvalorização que com o passar do tempo até mesmo pessoas resistentes tendem a manifestar sofrimentos psíquicos. (HELOANI e CAPITÃO, 2003; RODRIGUES, ALVARO e RONDINA, 2006).

Neste sentido, a Psicologia na vertente de saúde e doença no âmbito do trabalho tem buscado verificar o histórico prévio de vida de cada indivíduo e suas demandas que possam causar sofrimento no trabalho relacionado possivelmente ao excesso de trabalho de exigências enfrentadas diariamente pelos professores, sua representação sobre o próprio trabalho e condição psicossocial. E, se nesse caso, a representação está intimamente ligada a aquilo que o sujeito tem constituído ao longo da sua trajetória de vida e profissional, o sentido está vinculado aos ganhos que o fazer docente pode gerar no sujeito. Neste sentido, Souza, Petroni e Andrada (2013), identificaram em docentes a percepção de que o sofrimento é predominante, sendo decorrente de frustrações pelas expectativas e desejos não realizados, de modo que "sentimentos bons e ruins se misturam e se confundem: ora os professores se sentem aceitos e reconhecidos, ora sofrem e se frustram ao não receberem retorno do seu trabalho". (SOUZA, PETRONI e ANDRADA, 2013, p. 535).

Diante disso, o tema "mal-estar docente" ${ }^{4}$ " tem sido amplamente discutido interdisciplinarmente pela literatura psicológica, com vistas a "descrever os efeitos permanentes de caráter negativo que afetam a personalidade do professor, como resultado das condições psicológicas e sociais que se exercem na docência”. (MOSQUERA, STOBÄUS E SANTOS, 2007, p. 263); com efeitos negativos sobre o psicológico e social do docente, sob a forma de sintomas e sinais, como um alto índice de absenteísmo, falta de compromisso, um desejo anormal de férias, baixa autoestima, depressão, perda de significado da profissão e outros fenômenos psíquicos. (ESTEVES, 1999); e se tratando de um "fenômeno decorrente da mudança na política pública educacional o qual se

\footnotetext{
${ }^{4} \mathrm{O}$ tema do mal-estar docente na literatura tem tido nacionalmente, ainda na década de 80 , uma grande contribuição de M. Lipp (2011) com seus trabalhos na UNICAMP, em Campinas. Neste cenário, no sul do Brasil, destacam-se como principais referências na discussão sobre mal-estar/bem-estar docente os nossos trabalhos de MOSQUERA, STOBÄUS e SANTOS (2007), com repercussão mundial do tema.
} 
relaciona ao ambiente profissional do professor, estando presentes deficiências nas condições de trabalho" (ESTEVE, 1995, 1999 apud SILVA e CARVALHO, 2011, p. 3); além dos fatores ${ }^{5}$ acima, se somam as condições estruturais de trabalho (ausência de espaço para descanso/repouso, ausência de sala individual de trabalho, inadequação do local e de equipamentos, dentre outros) (ARAÚJO, et al., 2005; SILVA E CARVALHO, 2011).

\section{Método}

\section{Tipo de Pesquisa}

Caracteriza-se a presente no campo científico teórico-metodológico, com objetivo exploratório, pois busca-se obter uma visão geral do tipo aproximativo sobre as representações e sentidos da docência em professores universitários, partindo de uma revisão bibliográfica e de campo; sob abordagem qualitativa pelo enfoque de análise e interpretação dos dados obtidos durante a pesquisa de campo (GIL, 2008).

\section{Participantes}

Fizeram parte deste estudo 04 (quadro) docentes de uma faculdade privada de Cacoal - RO, sendo 02 Homens e 02 Mulheres, com idades entre 31 e 50 anos, de áreas de atuação e qualificações diversificadas, com a média de 3 anos de atuação no ensino superior, com jornada de trabalho de 40 horas semanais. Respeitando o sigilo dos sujeitos entrevistados, os mesmos serão nomeados como de 1 a 4, seguido do sexo e idade.

\section{Materiais e Procedimentos}

A coleta dos dados foi realizada no campus da faculdade, junto a professores voluntários que, após serem esclarecidos sobre os objetivos da pesquisa, assinaram o Termo de Consentimento Livre e Esclarecido, autorizando a utilização dos dados contidos no questionário (em anexo). Para a coleta de dados, foi utilizado um questionário semiestruturado de base para as entrevistas gravadas em áudio e transcritas para o documento Word, para posterior Análise de Conteúdo de Bardin (2004), que se organiza

\footnotetext{
5 Outras pesquisas sobre o mal-estar docente podem ser verificadas em: Lima (2010), na pesquisa "Condições de trabalho e saúde do professor universitário: estudo de caso de uma IFES; Reis, Carvalho, Araújo, Porto e Neto (2005), na pesquisa “Trabalho e distúrbios psíquicos em professores da rede municipal de Vitória da Conquista, Bahia, Brasil; Castro e Stahl (2012), na pesquisa "A voz dos professores de uma IES pública: desafios da prática docente na trajetória formativa e identitária"; Mosquera, Stobaus e Dornelles Jr (1996), na pesquisa “O mal-estar na docência: causas e consequências”.
} 
nas fases de pré-análise, exploração e, finalmente, tratamento dos resultados, onde se abre a oportunidade de propor inferência e a interpretação das informações obtidas nas entrevistas realizadas. Para análise dos dados foram propostas as seguintes categorias ${ }^{6}: 1$ - Significados e Sentimentos frente ao ato docente; 2 - Problemas vivenciados e ato docente; 3 - Estratégias de lidar com o mal-estar docente.

\section{Resultados e discussão}

A partir do problema e objetivos da pesquisa, apresentaremos em seguida os dados coletados e classificados de acordo com as categorias abaixo:

\section{Significados atribuídos ao trabalho docente em nível superior}

A partir da noção de que "Cada professor é uma história, viveu um caminho, construiu um percurso humano e profissional" (LODI, 2013, p. 53), torna-se importante analisar o significado do trabalho docente em nível superior para os entrevistados. Conforme apontado pela literatura, cada profissional atribui um significado diferente ao trabalho realizado, com se observa abaixo ${ }^{7}$ :

"Responsabilidade, muita responsabilidade [...] é uma responsabilidade muito grande por que eles estão ali plantado para futuramente eles colherem o futuro mesmo profissional eu vejo que a gente tem uma parcela de grandiosa responsabilidade pro futuro dessa juventude". Sujeito $1(\mathrm{~F}, 37)$.

"Olha é uma tarefa difícil hoje visto que a educação no país, ela sofre desde o ensino fundamental a falta de bagagem [...] ser professor de nível superior pra mim é vencer essas dificuldades, um trabalho, uma tarefa bem árdua pra resgatar esses alunos e dar a eles condições de poder ter uma profissão digna. Sujeito $2(\mathrm{M}, 33)$.

"Trabalho docente para o professor significa o seu aperfeiçoamento na matéria principalmente. Sujeito 3 (M, 51).

Significa pra mim trabalhar com amor apesar dos pesares pra mim significa ter a consciência que eu estou transformando, transformando não, mas tentando transformar os acadêmicos em profissionais [...] ser professor é um sacerdócio. Sujeito 4 (F, 30).

${ }^{6}$ Segundo a Análise de Conteúdo, as categorias podem ser a priori (antes da coleta e análise de dados) ou a posteriori, ambos os formatos, definidos pelos pesquisadores.

${ }^{7}$ Grifos dos pesquisadores 
Com base no exposto, as respostas nos levam a perceber que os professores se sentem responsáveis com a formação profissional dos alunos, devendo, para isso, estar compromissados com o aperfeiçoamento profissional. Nota-se ainda uma visão romântica da profissão, quando o Sujeito 4 (F, 30) fala do trabalho com "amor", ainda que as circunstâncias não sejam ideais. Isso nos faz lembrar Gauthier (1999 apud PASCHOALINO, 2007, p. 3) ao descrever o papel do docente como um sedutor de “mentes e coração ao mesmo tempo". É válido frisar que o Sujeito 2 (M, 33) entende enfaticamente ser o trabalho docente uma "tarefa difícil" diante da responsabilidade do professor para com a formação de novos profissionais. A literatura corrobora esse entendimento, pois conforme Castro e Stahl (2012), exige-se do docente que seja um profissional ativo, crítico e atento às inovações, porém, tais mudanças causam no docente sentimento de incerteza diante das responsabilidades que se apresentam.

Ainda nesse sentido, Paschoalino (2007, p. 8) destaca que "a sociedade espera a atuação do super-herói, ao projetar na figura do professor o protótipo de salvador das juventudes". Notamos ainda, nos sujeitos, a consciência da carga de responsabilidade, pois "o professor sente o peso de uma cobrança, já tradicional na profissão, que traz a expectativa de que o professor seja agente transformador da sociedade através da educação" (PASCHOALINO, 2007, p. 7). Interessante que tal senso de responsabilidade, idealismo e trabalho árduo, ganha conotações de uma função sacerdotal, na fala do sujeito 4, o que remete a certo imaginário que ainda permeia o ato docente como "missão", uma atividade nobre, e guarda, em certa medida, uma relação com a função antiga dos sacerdotes e sábios que educavam o ser humano e não apenas o profissional; ou seja, o professor assume seu trabalho incorporando o valor de sacerdócio" (PASCHOALINO, 2007, p. 3), no mesmo sentido, de Carlotto (2003, p. 12): “já houve um tempo em que se considerava a profissão docente um sacerdócio, uma vocação de abnegação e de dedicação quase heroica".

\section{Elementos que proporcionam satisfação e motivo em ser docente}

Ao serem questionados sobre que o lhes proporciona satisfação em ser docente, os entrevistados expressaram o que segue transcrito: 
explicado, participando [...] satisfação maior de ter o prazer de estar interagindo, de estar aprendendo e ensinando que ao mesmo tempo isso pra mim vale tudo". Sujeito 1 (F, 37).

“[...] é satisfatório quando a gente termina um período e percebe que o aluno conseguiu absorver aquilo que agente tentava passar para ele [...] quando um aluno chega e mostra pra gente que ele conseguiu absorver o conteúdo é muito satisfatório. Muito bom". Sujeito $2(M, 33)$.

"A gratificação com o aluno, a gratificação com a troca do respeito e da amizade que o aluno tem com o professor". Sujeito $3(\mathrm{M}, 51)$.

"[...] minha satisfação enquanto professora é chegar ao final de um certo período de prazos e a gente observar que o aluno conseguiu chegar a pelo menos nos conceitos básicos que você tem [...] me deixa feliz enquanto docente quando um acadêmico meu sai, deixa a instituição, passa em um concurso público, tem sucesso no trabalho, sucesso financeiro, então eu termino me sentindo meio co-participante desse sucesso do meu aluno". Sujeito 4 (F, 30).

É possível observar nas falas dos entrevistados evidência da satisfação em ser docente, o que é percebido quando relatam prazerosamente a "participação", a “interação", a "apreensão dos conteúdos", o "respeito" e a "amizade dos alunos". O Sujeito 4 (F, 30), deixa isso claro ao demonstrar a satisfação em constatar o sucesso profissional dos acadêmicos. Essencialmente, proporciona satisfação aos docentes atingirem os objetivos traçados quanto à formação dos alunos. Com relação aos motivos para serem professores universitários na atualidade, os sujeitos entrevistados apresentaram as seguintes posições:

“Aptidão pessoal nasci pra isso agora tenho certeza disso. Ver o crescimento dos acadêmicos no que eu faço e creio que a alegria que é minha motivação ver não só minha alegria em estar trabalhando com isso mais ver a alegria também dos acadêmicos em receber os ensinamentos isso me alegra bastante". Sujeito 1 (F, 37).

“[...] o professor universitário ele recebe um salário razoável então ele tem um certo respeito pelo salário que ele recebe e também pelo conhecimento que ele tem que não é muito comum no nosso país, tantas pessoas que tem o conhecimento, então a terceira que eu, o terceiro motivo pra ser professor universitário, olha é a alegria de ensinar eu acho, é interessante ensinar [...]. Sujeito 2 (M, 33).

"Três motivos, o primeiro seria o salário, o segundo o nível alto de intelectualidade e o terceiro seria novamente a gratificação do aluno com o professor". Sujeito 3 (M, 51).

“[...] não me vejo fazendo outra coisa porque eu sou professora por opção eu acho que não é por nenhum motivo de salário, é por que eu gosto da 
relação com o aluno [...] eu sou porque eu gosto de ser eu não tenho um motivo". Sujeito 4 (F, 30).

Notamos que para o Sujeito 1 (F, 37), os motivos para ser docente estão na "aptidão pessoal", parecendo se referir a algo como um dom ou talento natural, na "alegria" de ensinar e de ver o crescimento do aluno. Já o Sujeito 2 (M, 33) é motivado pelo "salário", pelo "conhecimento" e pela "alegria" de ensinar. Nesse mesmo sentido, revela o Sujeito $3(\mathrm{M}, 51)$ ser motivado pelo "salário", "nível de intelectualidade" e pela relação aluno - professor, no que poderia apontar certa valorização da dimensão afetiva dessa interação. Por fim, o Sujeito 4 (F, 30) sente-se motivado pelo prazer no exercício da profissão, pois "gosta de ser", o que parece remeter a certos ganhos subjetivos associados à prática docente, mas que não foram mencionados pelo sujeito. Nesse sentido, para Martins e Oliveira $(2006,232)$ “o prazer é definido a partir de dois fatores: valorização e reconhecimento no trabalho". Notadamente, explícita e implicitamente, o prazer em se fazer docente pode ser percebido na fala dos sujeitos.

\section{Conhecimento do termo "Mal-estar docente" e seus Fatores Causais}

Com a finalidade de analisar a presença de elementos geradores de "mal-estar docente”, foi questionado aos sujeitos a respeito do referido termo, os possíveis fatores causadores e as formas encontradas pelos sujeitos de lidarem com a situação. Dessa forma, buscando-se identificar o tipo de conhecimento dos sujeitos a respeito do termo, os entrevistados foram convidados a falarem sobre o tema:

"É o mal-estar docente pra mim é o cansaço [...] pra mim causa malestar quando tenho muitas tarefas diárias e que as vezes não estou dando conta." Sujeito $1(\mathrm{~F}, 37)$.

“Mal-estar-docente, infelizmente eu não conheço." Sujeito 2 (M, 33).

"O mal estar docente, pra mim que eu entendo é exatamente a falta de compromisso do aluno em relação ao professor." Sujeito 3 (M, $51)$.

"Eu nunca ouvi esse termo, mas eu acredito que quando a pessoa é docente e ele não tem o perfil pra aquilo e termina não estando satisfeito [...]". Sujeito 4 (F, 30).

O Sujeito $1(\mathrm{~F}, 37)$ concebe o mal-estar docente como "cansaço" e o Sujeito 3 (M, 51) como a "falta de compromisso do aluno", já o Sujeito $2(\mathrm{M}, 33)$ desconhece o termo ao afirmar "não conheço". Embora o Sujeito 4 (F, 30) "não conheça o termo", procura exemplificá-lo, como a falta de "perfil” para a profissão. Referindo-se à expressão "mal- 
estar docente" aos diversos problemas envolvidos no ato e papel docente, os sujeitos relatam ter vivenciado alguma situação de manifestação em suas carreiras atualmente:

"Saúde, atualmente faz dois meses que eu estive uma semana de licença eu creio que é por causa do estresse e minha imunidade [...] creio que não é só comigo, é eu creio que é algo que acomete todos os docentes." Sujeito 1 (F, 37).

"Acontece muito quando a gente percebe que o aluno não tem condição, por exemplo de acompanhar a disciplina e ele começa a fazer pedidos para o professor facilitar ou dar três pontos." Sujeito $2(\mathrm{M}, 33)$.

"O mal docente pra mim é exatamente a falta de hierarquia, os alunos quando tem problema em relação ao aprendizado da matéria, eles não falam com o professor, eles procuram já diretamente a coordenação ou a direção.” Sujeito $3(\mathrm{M}, 51)$.

“[...] eu já me senti uma vez quando eu tive que ministrar uma disciplina, fui meio que obrigada a ministrar uma disciplina que não era da minha área, isso torna insegura." Sujeito $4(\mathrm{~F}, 30)$.

Observamos na fala dos sujeitos elementos caracterizadores do "mal-estar" no ato docente, os quais são contemplados pela literatura, conforme Raitz e Silva (2014, p. 205), “[...] esses sujeitos (os docentes de ensino superior) têm vivido uma sobrecarga no trabalho e processos psicossociais que podem afetar sua saúde e bem-estar no exercício da profissão". Notamos que os docentes têm uma nítida percepção dos reveses da profissão, daquilo que lhes traz incômodos e inquietações, bem como das consequências das experiências vivenciadas, muitas delas sentidas no próprio "corpo". E nesse aspecto, consideramos ainda que "o professor sofre por não conseguir vivenciar as expectativas em relação ao seu trabalho, associadas às características das dimensões de persuadir, de encantar seu aluno no conhecimento, pela fé no outro e de ter a vocação para a difícil, ‘impossível' (FREUD, 1930/1969), a tarefa de ensinar” (PASCHOALINO, 2007, p. 7). Acrescentamos que Esteve (1999, p. 60) realizou estudos a partir das fontes de tensão, a exemplo das referidas pelos sujeitos, entendendo que cada docente atribuirá significado diferente, sendo que: "Essa mesma implicação pessoal que antes aparecia como fonte de autorealização apresenta, portanto, ao educador, uma ambivalência; tornando-se paradoxalmente a cara e a cruz de sua atividade educadora.

A partir do relato do Sujeito $2(\mathrm{M}, 33)$, podemos notar que as relações com o aluno afetam diretamente o critério de "julgamento" docente, o que lhe causa "mal-estar". O mal-estar docente recebe as seguintes atribuições pelos sujeitos entrevistados: 
"É acumulo de tarefas, responsabilidade eu acho que as vezes até mal distribuídas no sentido assim, as vezes algumas burocracias que podiam, deveria ser evitadas, as vezes uns nãos que poderiam não existir [...] falta um pouco de uma visão geral da gestão em relação a percepção daquilo que é necessário para o bem-estar do professor[...]." Sujeito $1(\mathrm{~F}, 37)$.

"Como eu já disse várias vezes a falta de conhecimento por parte do aluno, prévio para poder cumprir o ensino superior. Ser docente é algo que envolve muito sacrifício não pode pensar que vai acontecer apenas trabalho na faculdade, esse trabalho vai para casa, a gente vai ter momentos de estresse e esses momentos vão ser levados para casa também.” Sujeito $2(\mathrm{M}, 33)$.

“[...] esse problema é gerado por falta de hierarquia, não respeitar primeiramente o professor que está ali na frente com eles, exatamente a falta de hierarquia que o aluno não tem noção hoje em dia." sujeito 3 (M, 51).

“A gente é levado a ter que ministrar aquela disciplina porque não há outro professor com área mais próxima, então querendo ou não é uma situação desconfortável." Sujeito 4 (F, 30).

O Sujeito $1(\mathrm{~F}, 37)$ atribui o mal-estar aos elementos institucionais, tais como as "burocracias", "responsabilidades", "acúmulos de tarefa", não atenção às "necessidades" do professor" e aos "nãos" desnecessários. O Sujeito 2 (M, 33) atribui o mal-estar ao "aluno", por não estar preparado para cursar o ensino superior, ao "sacrifício" da profissão, ao "estresse" e ao "trabalho", que não fica somente na universidade. Já o Sujeito 3 (M, 51) atribui o mal-estar à "falta de hierarquia” por parte dos alunos. Por sua vez, o Sujeito 4 (F, 30) relata ser uma "situação desconfortável" ministrar aulas de disciplinas com as quais não tem afinidade, isso nos faz lembrar os autores Martins e Oliveira (2006, p. 234): “O trabalhador tem de fazer o que não fazia antes, e esta diferença pode implicar reprovação, que não passa pela questão moral ou social, ou de culpa do superego, mas é uma traição do próprio eu, um risco de perder a identidade". A literatura embasa os elementos mencionados pelo Sujeito 1 (F, 37) ponderando que "certas condições de trabalho fazem emergir um sofrimento que pode ser atribuído ao choque entre uma história individual, portadora de projetos, de esperanças e de desejos e uma organização do trabalho que os ignora" (LIMA, 2010, p. 29). Os entrevistados ainda relataram fatores que proporcionam insatisfação em ser docente, afirmando que:

"A insatisfação, eu não digo minha insatisfação eu já até falei mais assim, eu vejo que a falta de incentivo, incentivo as vezes pra pesquisa, incentivo de auxílio, mesmo financeiro, assim um incentivo em crescer mesmo profissionalmente, as vezes eu me sinto um pouco assim, sem esse apoio institucional em buscar isso.” Sujeito 1 (F, 37). 
“[...] causa insatisfação muitas vezes quando o aluno não tem conhecimento necessário para poder absorver aquilo que a gente tem para passar para ele [...]." Sujeito $2(\mathrm{M}, 33)$.

"Insatisfação é o pouco compromisso que o aluno tem junto com a disciplina que o professor ministra." Sujeito 3 (M, 51).

"[...] as vezes os alunos, principalmente quando é uma instituição privada, tem o hábito de achar que o professor é empregado do aluno [...] a gente está aqui a serviço de transferir o conhecimento de fazer com que o acadêmico seja alguém melhor e construa parte daquele conhecimento que vai ser levado." Sujeito 4 (F, 30).

A partir do relato dos docentes entrevistados, observa-se que a insatisfação com a profissão está centrada em dois aspectos: postura do aluno e instituição de ensino. No tocante à instituição, o Sujeito 1 (F, 37) menciona a "falta de incentivo", ou seja, o pouco incentivo ao desenvolvimento de projetos, pesquisas e outras atividades que favoreçam o crescimento profissional. Com relação ao aluno, nota-se insatisfação com a postura do aluno quanto ao comprometimento com a disciplina e em relação ao docente, o que pode ser observado quando o Sujeito $(\mathrm{M}, 51)$ fala do "pouco compromisso que o aluno tem" e, ainda, o aluno não dispor de conhecimentos básicos que permitam o desenvolvimento e construção de novos conhecimentos, conforme relatado pelo Sujeito 2 (M, 33). Já tratando-se dos motivos para não ser professor universitário na atualidade, observamos posições diversas:

"Particularmente, eu não elencaria não, hoje em dia, as barreiras existe (sic) mas eu particularmente não elencaria nenhum motivo." Sujeito 1 $(\mathrm{F}, 37)$.

"Não tem como que vou, três motivos pra ser e eu não consigo ver três motivos pra não ser [...]." Sujeito 2 (M, 33).

"A falta de hierarquia do aluno com o professor [...]. A falta de compromisso do aluno com a matéria que o professor ministra. A cobrança da instituição junto ao professor." Sujeito 3 (M, 51).

"Motivos pra não ser se você for pensar direitinho, o salário não é grande coisa, o segundo o desgaste que a gente tem por que no meu caso eu tenho muitas disciplinas [...] em terceiro é que às vezes os alunos não compreendem que a mão mais pesada do professor é pra forçá-los a ter um tipo de conhecimento [...]." Sujeito 4 (F, 30).

Os sujeitos $1(\mathrm{~F}, 37)$ e $2(\mathrm{M}, 33)$ não conseguem vislumbrar desmotivos para a profissão, por outro lado, o Sujeito $3(\mathrm{M}, 51)$ vê dificuldades com a "falta de hierarquia do aluno" e "falta de compromisso do aluno", mas também "cobrança da instituição". Já o Sujeito 4 (F, 30) coloca o "salário", o "desgaste" e a postura dos alunos como elementos desmotivadores da profissão. Na fala do Sujeito 4 (F, 30) observamos a presença do “desgaste", fator este que nos remete aos escritos de Martins e Oliveira (2006, p. 232), 
para quem “o sofrimento é definido a partir do fator desgaste que é a sensação de cansaço, desânimo e descontentamento com relação ao trabalho”. Nessa ótica, Esteve (1984, 1994, 1999 apud MOSQUERA, STOBÄUS e SANTOS, 2007, p. 264-265) compreende que existem dois tipos de fatores promotores do mal-estar na docência, quer sejam:

Fatores de primeira ordem: Recursos materiais e condições de trabalho; Violência nas instituições escolares; Esgotamento docente e acúmulo de exigências sobre o professor. São desdobramento dos anteriores. [...] Fatores de segunda ordem: Modificação no papel docente e de agentes tradicionais de socialização; A função docente: contestação e contradições; Modificação do apoio do contexto social; os objetivos do sistema de ensino e os avanços dos conhecimentos; e A imagem do professor.

Em síntese, observamos nas falas dos sujeitos em toda esta subcategoria elementos que se enquadram tanto nos "fatores de primeira ordem" quanto nos de "segunda ordem", conforme nos aponta Esteve, que os fatores causadores do "mal-estar" podem ser: "acúmulo de tarefas", "estresse", "problema", "situação desconfortável", "falta de incentivo", "insatisfação", "professor é empregado". Sem dúvidas, tais aspectos refletem a imagem que se tem do professor, o esgotamento, violência institucional, acúmulo de exigências.

\section{Formas de lidar com "Mal-estar docente"}

Outro aspecto importante é averiguar a forma encontrada pelos sujeitos de lidarem, em termos de sentimentos e ações, com o mal-estar tratado no tópico anterior.

"No trabalho eu consigo manter o domínio [...] em casa eu choro, choro, extravaso [...] percebo que a saúde é um dos que eu extravaso que é quando cai a imunidade eu sinto dores de cabeça." Sujeito 1 (F, 37).

"A parte emocional ela abala bastante, mas isso eu acredito que aconteça em qualquer outro trabalho, qualquer outro serviço, a pessoa ela vai ter momentos que ela vai estar um pouco estressada vai ficar angustiada [...] mais sempre acontece com a gente, momentos de prazer no serviço que é o que mais acontece, então isso faz com que a gente mantenha a profissão." Sujeito 2 (M, 33).

"Sentimento ao meu ver tem que ser superado pela troca do reconhecimento que ele tem com o professor isso aí é um elogio que o aluno proporciona ao professor, esse sentimento supera esse tipo de mal estar que é provocado. ” Sujeito 3 (M, 51).

"Na visão geral é que quando o professor está dando aula ele está consciente que pode ter uma troca positiva com o aluno e que pode ter uma troca negativa [...] então o professor tem que estar consciente disso, que isso pode acontecer." Sujeito 3 (M, 51).

"Eu acho que eu sou muito passional [...] a gente não é super-herói pra resolver tudo [...] porque quando você gosta de fazer aquilo e você não alcança teu objetivo você tem um sentimento de frustração né. " Sujeito 4 (F, $30)$. 
O Sujeito $1(\mathrm{~F}, 37)$ lida com a situação procurando aparentar equilíbrio no ambiente de trabalho, porém, no ambiente familiar revela suas emoções, conforme afirma "em casa eu choro", além disso, apresenta evidências disso na sua "saúde". Isto nos permite entender que, para manter o ambiente de trabalho protegido do "mal" sofrido, o sujeito acaba afetando suas relações familiares e a sua saúde. O Sujeito 2 (F, 37) sente que o seu "emocional" abalado é contrabalanceado com o "prazer" proporcionado pela profissão. O Sujeito $3(\mathrm{M}, 51)$ afirma que o profissional deve estar "consciente" do retorno positivo ou negativo em sua prática e que isso pode ser superado com o "reconhecimento" profissional. Já o Sujeito 4 (F, 30) menciona ser "passional" com relação aos problemas, demonstrando aparentemente ser indiferente às dificuldades, no entanto, deixa evidência de sua insatisfação ao mencionar a "frustração". A fala do Sujeito 3 (M, 51) vai ao encontro do que afirma Silva e Carvalho (2011, p. 7): “o professor, para minimizar o mal-estar advindo do exercício de uma atividade de trabalho em que se esvaem suas energias, procura formas para escapar do mal que se abate sobre ele".

Torna-se relevante salientar que atualmente estudos são desenvolvidos com a intenção de identificar elementos caracterizadores do "mal-estar", afim de tratar o enfoque da sua prevenção, fazendo o uso de "estratégias de apoio em direção ao bemestar, com repercussões na formação enquanto futuro educador e pessoa como discente, e nos aspectos de sua atuação profissional e pessoa". (MOSQUERA, STOBÄUS e SANTOS, 2007, p. 260).

Por fim, retomamos Esteve (1999, p. 144) para quem "enfrentar de forma efetiva o mal-estar docente, onde se deve atuar prioritariamente é sobre suas condições de trabalho e sobre o apoio que o professor recebe para realizá-lo".

\section{Considerações Finais}

Tratando-se da categoria significado e sentimentos frente ao ato docente, constatamos que cada profissional atribui significado ao trabalho docente em nível superior, no entanto, notamos: a consciência da "carga" de responsabilidade do professor e da cobrança exercida pelo aluno, pela instituição e sociedade, além de um agir docente preocupado com a formação profissional dos alunos, mas também certo idealismo em relação à profissão. Ainda neste aspecto, verificamos que atingir os objetivos traçados quanto à formação dos alunos, contemplando o seu "sucesso profissional", proporciona 
satisfação aos docentes, bem como satisfação na "participação", na "interação", na “apreensão dos conteúdos", no "respeito" e na "amizade".

Com relação aos problemas vivenciados e ato docente, percebemos elementos caracterizadores do "mal-estar docente", embora o termo não seja comum aos docentes analisados, mas tenham consciência do que vêm a ser, se referindo a situações vivenciadas e que eles têm nítida percepção dos reveses da profissão, daquilo que lhes traz incômodos: "acúmulo de tarefas", "cansaço", "Responsabilidade", "falta de compromisso do aluno", "estresse", "falta de hierarquia na instituição e na resolução de conflitos entre professores e alunos".

Quanto às formas de lidar com "Mal-estar docente", em termos de sentimentos e ações encontradas pelos professores, constatamos posturas diversas que variam entre a indiferença e a preocupação excessiva com as dificuldades peculiares ao ato docente. Verificamos que muitas vezes o "emocional" abalado do docente é contrabalanceado com o "prazer" proporcionado por outros elementos da profissão.

Nesta abordagem qualitativa sobre as representações da docência, não buscamos generalizar os dados para toda a categoria profissional docente do ensino superior, mas uma análise e interpretação dos dados obtidos para/no público escolhido, num determinado contexto delimitado. Nesse sentido, acreditamos que a Psicologia pode auxiliar os profissionais da docência a reencontrar e/ou ressignificar o sentido/significado da profissão, analisando para isso as representações da docência por aquele público.

\section{Referências}

ARAÚJO, T. M.; I. P., VIENA, M. A.; ARAÚJO, E. M. Mal-estar docente: avaliação de condições de trabalho e saúde em uma instituição de ensino superior. Revista Baiana de Saúde Pública, 2005.

BARDIN, Laurence. Análise de conteúdo. 3. ed. Lisboa: Edições 70, 2004.

CASTRO, A. M. B.; STAHL, L. R. A voz dos professores de uma IES pública:desafios da prática docente na trajetória formativa e identitária. In: IX ANPED SUL, 2012, Caxias do Sul. Anais eletrônicos. Caxias do Sul: UCS, 2012. Disponível em: $<$ http://www.ucs.br/etc/conferencias/index.php/anpedsul/9anpedsul/paper/viewFile/266 8/508>. Acesso em: 30 jan. 2017

CARLOTTO, Mary Sandra. Burnout e o trabalho docente: considerações sobre a intervenção. Revista Eletrônica InterAção Psy. Ano 1, n. 1. Ago 2003. < 
http://www.saudeetrabalho.com.br/download_2/burnout-professor.pdf $>>$. Acesso em: 30 jan. 2017

DEJOURS, Christophe. A loucura do trabalho: estudo de psicopatologia do trabalho. 5. ed. São Paulo: Cortez, 1992.

ESTEVE, José Manuel Zaragoza. O mal-estar docente: a sala de aula e a saúde do professor. 3. ed. Baurú: Edusc, 1999.

FREUD, Sigmund (1930). O Mal-Estar na Civilização. Tradução Paulo César de Souza, São Paulo: Penguin Classics Companhia das Letras, 2011.

GIL, Antonio Carlos. Métodos e técnicas de pesquisa social. São Paulo: Atlas, 2008.

HELOANI, J. R.; CAPITÃO, C.G. Saúde mental e psicologia do trabalho. São Paulo em perspectiva, [online], v. 17 , n. 2, p. 102-108, 2003. Disponível em: < http://www.scielo.br/pdf/spp/v17n2/a11v17n2>. Acesso em: 30 jan. 2017.

JACQUES, Maria da Graça Corrêa. Abordagens teórico-metodológicas em saúde/doença mental \& trabalho. Psicologia \& Sociedade, Belo Horizonte, v. 15, n. 1, p. 97-116, janjun. 2003. Disponível em: $\quad$ http://www.scielo.br/scielo.php?pid=S010271822003000100006\&script=sci_abstract\&tlng=pt>. Acesso em: 30 jan. 2017.

LIMA, M. F. E. M. Condições de trabalho e saúde do professor universitário: estudo de caso de uma IFES. Desafio: Revista de Economia e Administração. Campo Grande, MS, v. 11, n. 23, p. 25-35, jan/abr. 2010.

LIPP, Marilda. Pesquisas sobre stress no Brasil. 2. ed. Campinas: Papirus, 2001.

LODI, Ivana Guimarães. Sobre o ofício de mestre: maneiras de ser e estar na profissão. Evidência, Araxá, v. 8, n. 9, p. 49-61, 2013.

MARTINS, A. C. A.; OLIVEIRA, G. Trabalho: fonte de prazer e sofrimento e as práticas orientais. In: VILARTA, Roberta; CARVALHO, Teresa Helena Portela Freire; GUTIERREZ, Gustavo Luis (Org.). Qualidade de vida e fadiga institucional. Campinas: IPES Editorial, 2006.

MOSQUERA, Juan José Moriño; STOBÄUS, Claus Dieter; DORNELLES JR, João. O mal-estar na docência: causas e consequências. In: Educação, Porto Alegre, v. 19, n.31, p. 139-146, 1996. Edipucrs: Porto Alegre, 1996.

PASCHOALINO, Jussara Bueno de Queiroz. A complexidade do trabalho docente na atualidade. [2007].

Disponível em: $<$ http://www.senept.cefetmg.br/galerias/Arquivos_senept/anais/quarta_tema6/Quart aTema6Artigo2.pdf $>$. Acesso em: 30 jan. 2017.

RAITZ, Tânia Regina; SILVA, Christie Dinon Lourenço. Trajetórias identitárias e sentidos do trabalho docente para professores universitários. Psicologia \& Sociedade, Belo Horizonte, ano 2014, vol. 26, n. 1. Disponível em: <http://www.scielo.br/pdf/psoc/v26n1/22.pdf> Acesso em: 30 jan. 2017. 
RODRIGUES, P. F.; ALVARO, A. L. T.; RONDINA, R. Sofrimento no trabalho na visão de Dejours. Revista Científica Eletrônica de Psicologia, Garça, ano IV, n. 7. nov. 2006. Disponível em: <http://faef.revista.inf.br/imagens_arquivos/arquivos_destaque/lh21p1iEajxlWcK_2013 -5-10-15-30-2.pdf $>$. Acesso em: 30 jan. 2017.

SILVA, W. R.; CARVALHO, N. M. S. O adoecimento do docente de ensino superior e a repercussão sobre a sua saúde e o ensino. In: $1^{\text {a }}$ SEMANA PEDAGÓGICA DA FACULDADE CATÓLICA DE UBERLÂNDIA, 2011, Uberlândia. Anais eletrônicos. Uberlândia, 2011. Disponível em: http://www.catolicaonline.com.br/semanapedagogia/resumo trabalhos/O\%20ADOECI MENTO\%20DO\%20DOCENTE\%20DE\%20ENSINO\%20SUPERIOR\%20WELLINGTON.pdf>. Acesso em: 30 jan. 2017.

SORATTO, Lúcia; OLIVIER-HECKLER, Cristiane. Os trabalhadores e seu trabalho. CODO, Wanderley (Coord). In: Educação: carinho e trabalho. Petrópolis: Vozes, p. 85-106, 2006

SOUZA, V. L. T.; PETRONI, A. P.; ANDRADA, P. C. A afetividade como traço da constituição identitária docente: o olhar da psicologia. Psicologia \& Sociedade, v. 25, n. 3, p. 527-537, 2013. Disponível em: <http://www.ufrgs.br/seerpsicsoc/ojs2/index.php/seerpsicsoc/article/view/3652 >.

Acesso em: 30 jan. 2017.

VIEIRA, C. E. C.; BARROS, V. A.; LIMA, F. P. A. Uma abordagem da psicologia do trabalho, na presença do trabalho. Psicologia em Revista, Belo Horizonte, v. 13, n. 1, p. 155-168, jun. 2007. Disponível em: http://www.pucminas.br/imagedb/documento/DOC_DSC_NOME_ARQUI2008052117 2519.pdf>. Acesso em: 30 jan. 2017.

\section{Como citar este artigo:}

ASSIS, Cleber Lizardo de.; PACHECO, Valdimari. Representações e vivências da docência em professores do ensino superior de uma faculdade privada de Cacoal/RO. Revista Ibero-Americana de Estudos em Educação, Araraquara, v.12, n.1, p. 37-53, 2017. Disponível em: 〈http://dx.doi.org/10.21723/riaee.v12.n1.7597>. E-ISSN: 19825587.

Data de submissão: jan/2015

Aprovação final: jan/17 